\title{
Care for frail older adults in the community: an integrative review
}

Gislaine Alves de Souza' $\mathbb{1 D}$ Karla Cristina Giacomin² (D) Josélia Oliveira Araújo Firmo 3 ID

\section{Abstract}

Objective: to identify scientific evidence regarding the care of frail older adults in the community, from the perspective of the older adults themselves. Method: a descriptive, integrative review study was performed. The search for articles was carried out in the Medline, Lilacs, Web of Science, Scopus and SciELO databases. The inclusion criteria were complete available articles; published between 2014 and 2019; written in Portuguese, English, Spanish or French; which had older adults as participants. Results: four categories of analysis emerged from the results: frailty from the perspective of frail older adults; priorities from the perspective of the older adults; the older adults' perspectives on care by services; and interpersonal relationships in the care of frail older adults. The perception of the older adults has specific characteristics, has maintaining their independence as a focus of care, signals the need to maintain interpersonal relationships, improve communication, and for actions of health education and people-centered services. Conclusion: these points demand the attention of care providers and policy services to improve care delivery and provide actions that are welcomed by this public.

\footnotetext{
Fundação Oswaldo Cruz, Instituto René Rachou (Fiocruz Minas), Núcleo de Estudos em Saúde Pública e Envelhecimento, Programa de Pós-graduação em Saúde Coletiva. Belo Horizonte, MG, Brasil.

2 Prefeitura de Belo Horizonte, Secretaria Municipal de Saúde. MG, Brasil.

3 Fundação Oswaldo Cruz, Instituto René Rachou (Fiocruz Minas), Núcleo de Estudos em Saúde Pública e Envelhecimento. Belo Horizonte, MG, Brasil.

Funding: Conselho Nacional de Desenvolvimento Científico e Tecnológico (CNPq), bolsa produtividade (Processo 302614/2011-7) e Coordenação de Aperfeiçoamento de Pessoal de Nível Superior - Brasil (CAPES) - Código de Financiamento 001.

The authors declare there are no conflicts of interest in relation to the present study.

\section{Correspondence}

Keywords: Health of the Aged. Frailty. Review Literature as Topic. Culturally competent Care. Perception. Frail Elderly. 


\section{INTRODUCTION}

The worldwide demographic phenomenon of population aging is a complex and heterogeneous process that, at an individual level, involves the interaction of multiple aspects ${ }^{1}$, including the possibility of aging with or without frailty ${ }^{2-4}$. Frailty is a polysemic, multidetermined and multidimensional concept $^{3-5}$ related to increased susceptibility to unfavorable health outcomes: illness, functional decline, falls, hospitalization and mortality ${ }^{5}$. In old age, biomedical knowledge assumes frailty to be a vulnerability to biopsychosocial and environmental stressors $^{2,3,5}$, correlated with a decrease in functional reserve, limitations in activities of daily living, an increased need for care ${ }^{6}$, as well as lower satisfaction with health and quality of life $\mathrm{fe}^{4}$.

Frail older adults make up the majority of those in need of formal, informal and health service care ${ }^{2.7}$. Therefore, this syndrome is a public health concern, as it requires integrated care ${ }^{2}$, and can be prevented and recoverable through appropriate interventions ${ }^{5}$. Care is a human condition that depends on the point of view of the individual receiving it ${ }^{8,9}$ Furthermore, care models centered on acute treatment are inadequate for the frail older population, as they usually disregard the specific configurations of this phenomenon in the community, its support systems and the individual involved ${ }^{3}$.

In addition, studies on this topic focus mainly on the association between the frailty syndrome and adverse outcomes ${ }^{10}$. Studies on the experience of frail older adults are rare and limited ${ }^{4,11,12}$, from the perspective of the population receiving care $^{8}$ and at the community level ${ }^{13}$. Thus, while fundamental, the perspective of frail older adults is relatively unknown ${ }^{14}$. Research that considers the opinions, values, attitudes, understandings, and coping strategies of frail older adults in planning and defining resources, care and interventions in the context of frailty ${ }^{2,4,715}$ are relevant to improving care and health care, and to adapting services and policies to the demands of this public ${ }^{5.16}$ to help achieve integrated care ${ }^{9.16 .17}$. Thus, the experience of frail older adults in care is of vital importance to improvements in care ${ }^{18}$.
Therefore, the present study seeks to identify the scientific evidence regarding care for the frail older person in the community, through the perception of older adults via an integrative review. The article aims to contribute to the synthesizing of evidence ${ }^{19}$ and improving the care of this population ${ }^{20,21}$.

\section{METHOD}

To obtain a synthesis of current literature, an integrative review was carried out. This method, performed in a systematic, orderly and evidence-based manner, allows the combination of several theoretical and empirical methodologies (experimental and nonexperimental) regarding a particular phenomenon. It starts with a guiding question, used to obtain a comprehensive and relevant picture of health care $^{19-21}$. This integrative review was based on the following steps: identification of the study problem; establishment of the literature search strategy; study selection based on inclusion and exclusion criteria; critical reading; content evaluation and categorization; analysis and interpretation of results; and presentation of the review ${ }^{19.20}$.

The guiding question was: what scientific evidence is there about the care process for frail older adults in the community, from the view of such individuals? The Medline, Lilacs, Web of Science, Scopus and SciELO databases were searched. The terms were matched with the use of the Boolean operator "and": frail elderly, standard of care, culturally competent care, care; elderly, care, frailty; older adults, care, frailty; frail older people, care; frailty, old, care. It was decided to keep the descriptors and keywords relevant to approximate the search to the researched subject. The perception of frail older adults living in the community about care was surveyed from reading the abstracts. The survey, carried out by three researchers, was performed in October and November 2018 and updated in December 2019.

Inclusion criteria were: full and freely available articles; publications from 2014 to 2019; works in Portuguese, English, French or Spanish. The flowchart of the article selection steps is shown in Figure 1. 


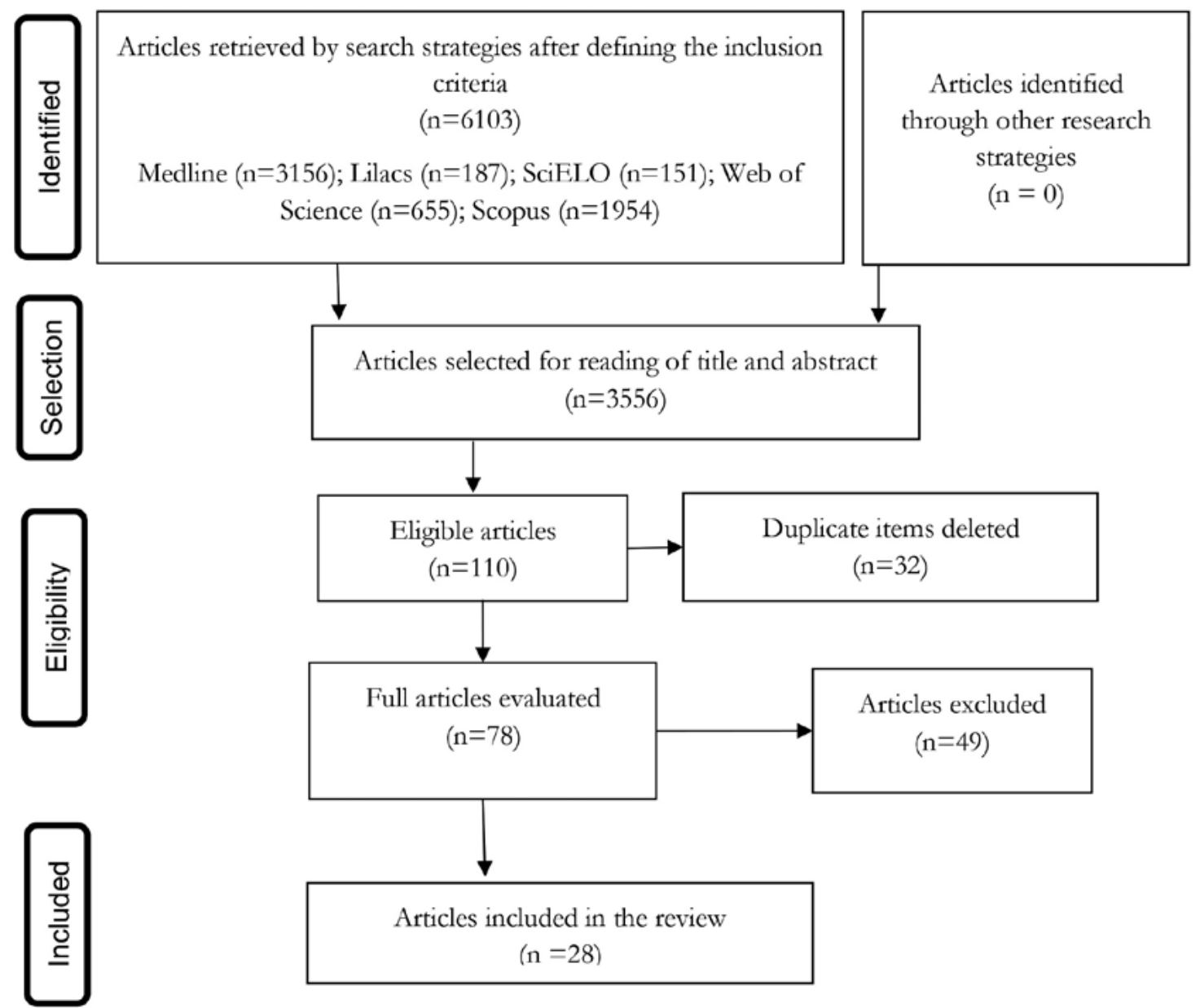

Figure 1. Flowchart of article selection based on the Prisma model. Belo Horizonte, Minas Gerais, Brazil.

In the screening, carried out by two researchers, articles that dealt with: validation of instruments and protocols; prevalence, interventions/programs and costs assessment; care models; association of frailty with specific symptoms and studies that dealt with the perception of the hospitalized or institutionalized older person. Those that included other participants, but where it was possible to distinguish the perception of older adults person in the community, were considered.

The selected articles were classified according to the levels of scientific evidence as proposed by Stetler et al. ${ }^{21}$, which comprise: level I - meta-analysis of multiple controlled studies; level II - individual experimental studies; level III - quasi-experimental studies; level IV - non-experimental studies such as descriptive correlational research, qualitative studies or case studies; level V - case reports and level VI opinion of recognized experts.

The articles were categorized by compiling: title; authors; year; periodical; country; language; method; sample; data collection and analysis procedure; key words; objectives; recommendations; limitations and the view of older people on care for frail older adults living in the community.

\section{RESULTS}

After reading the 3,556 abstracts, 110 articles were selected. After excluding the duplicate articles found by the different search strategies, 78 articles were found, which were read in full. Of these, 28 were incorporated into this review. The selected articles 
were all written in English ( $\mathrm{n}=28)$; mainly from Europe $(n=25)$. Fourteen articles exclusively studied the perception of older adults, and 15 publications included other participants.

Regarding the measurement of frailty, five articles used the Clinical Frailty Scale ${ }^{11,15,22-24}$, four

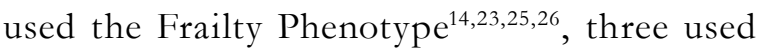
the Tilburg Frailty Indicator ${ }^{27-29}$, two used the Comprehensive Frailty Assessment Instrument ${ }^{10.30}$, five defined frailty without an instrument or objective measurement ${ }^{4.14 .31-33}$, one article used Prisma- $7^{6}$ and one the Edmonton Frailty Scale ${ }^{34}$. Of these, in two articles $^{14,23}$ there was the combination of more than one instrument. In nine articles, the measurement of frailty was not explicit ${ }^{18.35-42}$.

The evaluated articles predominantly had an evidence level of IV (27 articles), being qualitative, descriptive and cross-sectional studies, and one article corresponded to level III, quasi-experimental. Thus, the evidence level of the articles incorporated in this review is considered reasonable. Among the selected articles, $75 \%(\mathrm{n}=21)$ used qualitative methodologies, listed in Chart 1. Of these, 90.48\% used an interview as an instrument for data collection; one article used observational data and seven used a focus group. Explicitly thematic analysis and category coding was the most recurrent type of analysis $(n=12)$, and the Nvivo $(n=7)$ software package was the most used in these qualitative analyzes, followed by Atlas Ti $(n=3)$.

The use of quantitative methodologies represented $17.86 \%(n=5)$ of the articles, as summarized in Chart 2. In general, the authors of these articles used questionnaires, health screening instruments and scales to collect data. Four studies were crosssectional and one quasi-experimental. The SPSS software package was the statistical analysis tool mentioned in all the studies analyzed.

Of the quantitative-qualitative articles $(n=2)$, one collected data on the association of interviews and health screening instruments and one used a semistructured questionnaire, listed in Chart 3.

Chart 1. Qualitative articles analyzed, 2014-2019. Belo Horizonte, Minas Gerais, 2019.

\begin{tabular}{|c|c|c|c|}
\hline Objective & $\begin{array}{l}\text { No. of } \\
\text { older } \\
\text { adults }\end{array}$ & Sex & $\begin{array}{l}\text { Mean } \\
\text { age }\end{array}$ \\
\hline $\begin{array}{l}\text { Explore the influences on care preferences of frail older adults with recent acute } \\
\text { illnesses }{ }^{22} \text {. }\end{array}$ & 17 & $\begin{array}{l}10 \mathrm{~W} \text { and } \\
7 \mathrm{M}\end{array}$ & 84 \\
\hline $\begin{array}{l}\text { Explore the experiences of frail older adults with depression and anxiety and their views } \\
\text { on seeking help and ways in which services can be adapted to better meet their needs }{ }^{31} \text {. }\end{array}$ & 28 & $\begin{array}{l}\text { 19W and } \\
9 \mathrm{M}\end{array}$ & 80,71 \\
\hline $\begin{array}{l}\text { Explore opinions to determine whether there are effective daily strategies that can } \\
\text { be adopted to reduce, reverse or prevent frailty }{ }^{32} \text {. }\end{array}$ & 9 & $\begin{array}{l}6 \mathrm{~W} \text { and } \\
3 \mathrm{M}\end{array}$ & $73-89$ \\
\hline $\begin{array}{l}\text { Explore how slightly frail older people perceive health promotion and the factors } \\
\text { that affect behavior change } \mathrm{e}^{23} \text {. }\end{array}$ & 16 & $\begin{array}{l}13 \mathrm{~W} \text { and } \\
3 \mathrm{M}\end{array}$ & 80 \\
\hline $\begin{array}{l}\text { Explore health, health management and behavioral factors that contribute to } \\
\text { enabling high-risk patients to avoid unplanned hospitalizations }{ }^{35} \text {. }\end{array}$ & 21 & $\begin{array}{l}19 \mathrm{~W} \text { and } \\
12 \mathrm{M}\end{array}$ & $58-96$ \\
\hline $\begin{array}{l}\text { Investigate how people have managed to remain resilient as they age in remote } \\
\text { places, despite the gap in formal support services }{ }^{37} \text {. }\end{array}$ & 14 & $\begin{array}{l}\text { Not } \\
\text { reporter }\end{array}$ & $61-80$ \\
\hline $\begin{array}{l}\text { Explore the perceptions of behaviors undertaken by older adults with mild frailty } \\
\text { and the components for new health promotion services at home }{ }^{24} \text {. }\end{array}$ & 14 & $\begin{array}{l}8 \mathrm{~W} \text { and } \\
6 \mathrm{M}\end{array}$ & $75-94$ \\
\hline $\begin{array}{l}\text { Contrast the frail experiences of older adults with the perceptions of others about } \\
\text { existential loneliness }{ }^{33} \text {. }\end{array}$ & 15 & $\begin{array}{l}7 \mathrm{~W} \text { and } \\
8 \mathrm{M}\end{array}$ & 86 \\
\hline $\begin{array}{l}\text { To explore how frail older patients experience daily life one week after discharge } \\
\text { from acute hospitalization }{ }^{29} \text {. }\end{array}$ & 14 & $\begin{array}{l}7 \mathrm{~W} \text { and } \\
7 \mathrm{M}\end{array}$ & 80.6 \\
\hline $\begin{array}{l}\text { Explore the perceptions of older adults about frailty and their beliefs about its } \\
\text { progression and consequences }^{11} \text {. }\end{array}$ & 29 & $\begin{array}{l}17 \mathrm{~W} \text { and } \\
12 \mathrm{M}\end{array}$ & $66-98$ \\
\hline
\end{tabular}


Continuation of Table 1

\begin{tabular}{|c|c|c|c|}
\hline Objective & $\begin{array}{l}\text { No. of } \\
\text { older } \\
\text { adults }\end{array}$ & Sex & $\begin{array}{l}\text { Mean } \\
\text { age }\end{array}$ \\
\hline $\begin{array}{l}\text { Explore access to health and social care services for frail older adults to determine } \\
\text { the prospect of developing more accessible services }{ }^{36} \text {. }\end{array}$ & 9 & $\begin{array}{l}\text { Not } \\
\text { reported }\end{array}$ & $>2$ \\
\hline $\begin{array}{l}\text { Explore the experiences, understandings, meanings and malleability of frailty for } \\
\text { individuals; and describe the development of viable interventions in clinical practice }{ }^{15} \text {. }\end{array}$ & 25 & $\begin{array}{l}16 \mathrm{~W} \text { and } \\
9 \mathrm{M}\end{array}$ & $>2$ \\
\hline $\begin{array}{l}\text { Explore how older people with complex health problems experience frailty in their } \\
\text { daily lives }{ }^{38} \text {. }\end{array}$ & 10 & $\begin{array}{l}7 \mathrm{~W} \text { and } \\
7 \mathrm{M}\end{array}$ & 84 \\
\hline Examine perceptions and knowledge about frailty among older adults ${ }^{25}$. & 29 & $\begin{array}{l}21 \mathrm{~W} \text { and } \\
8 \mathrm{M}\end{array}$ & 76.3 \\
\hline Describe how existential loneliness was narrated by frail older adults ${ }^{26}$. & 22 & $\begin{array}{l}10 \mathrm{~W} \text { and } \\
12 \mathrm{M}\end{array}$ & 76-101 \\
\hline $\begin{array}{l}\text { Examine how older people deal with frailty in a transitional care program and } \\
\text { discuss the implications for improving service delivery }{ }^{18} \text {. }\end{array}$ & 20 & $\begin{array}{l}13 \mathrm{~W} \text { and } \\
7 \mathrm{M}\end{array}$ & 80 \\
\hline $\begin{array}{l}\text { Explore how older people living in disadvantaged neighborhoods deal with aging } \\
\text { issues }{ }^{40} \text {. }\end{array}$ & 20 & $\begin{array}{l}13 \mathrm{~W} \text { and } \\
7 \mathrm{M}\end{array}$ & 72.5 \\
\hline $\begin{array}{l}\text { To investigate the concept of perceived control related to health care from the } \\
\text { point of view of frail older adults }{ }^{14} \text {. }\end{array}$ & 32 & $\begin{array}{l}19 \mathrm{~W} \text { and } \\
13 \mathrm{M}\end{array}$ & $\begin{array}{l}65-84= \\
17 \geq 85 \\
=15\end{array}$ \\
\hline $\begin{array}{l}\text { Explore the experience of frail older people and case managers in a complex case } \\
\text { management intervention }{ }^{4} \text {. }\end{array}$ & 14 & $\begin{array}{l}10 \mathrm{~W} \text { and } \\
4 \mathrm{M}\end{array}$ & 83 \\
\hline $\begin{array}{l}\text { Develop an interpretative structure based on older adults' understanding of } \\
\text { independence and autonomy for receiving specialized care }{ }^{42} \text {. }\end{array}$ & 91 & $\begin{array}{l}68 \mathrm{~W} \text { and } \\
23 \mathrm{M}\end{array}$ & 80.8 \\
\hline $\begin{array}{l}\text { Explore the experience of meaning in life, as well as the loss of meaning for } \\
\text { socially frail older adults }{ }^{30} \text {. }\end{array}$ & 56 & $\begin{array}{l}34 \mathrm{~W} \text { and } \\
22 \mathrm{M}\end{array}$ & 79.3 \\
\hline
\end{tabular}

$\mathrm{W}=$ women and $\mathrm{M}=$ men; $*$ or age range, in years.

Chart 2. Qualitative articles analyzed, 2014-2019. Belo Horizonte, Minas Gerais, 2019.

\begin{tabular}{|l|l|l|l|}
\hline Objective & $\begin{array}{l}\text { No. of older } \\
\text { adults }\end{array}$ & Sex & Average age \\
\hline $\begin{array}{l}\text { Examine whether the perspectives of frail older adults living in the } \\
\text { community on the quality of primary care according to the dimensions } \\
\text { of the Chronic Care Model are associated with the productivity of } \\
\text { patient-professional interactions }{ }^{27}\end{array}$ & 464 & $336 \mathrm{~W}$ and \\
\hline $\begin{array}{l}\text { Examine loneliness, health-related quality of life and health complaints } \\
\text { regarding the use of outpatient health care among older adults living at } \\
\text { home }{ }^{39}\end{array}$ & $153 \mathrm{M}$ & 82.4 \\
\hline $\begin{array}{l}\text { Analyze the explanatory power of the variables that measure health } \\
\text { strengthening factors for self-rated health among frail older adults living } \\
\text { in the community }\end{array}$ & 161 & $102 \mathrm{~W}$ and & 81.5 \\
\hline $\begin{array}{l}\text { Describe care needs perceived as met and not met by frail older adults } \\
\text { using a multidimensional assessment tool and explore associations with } \\
\text { sociodemographic and health-related characteristics }\end{array}$ & 1,137 & $89 \mathrm{~W}$ and & $82 \mathrm{M}$ \\
\hline $\begin{array}{l}\text { Examine the health needs of older residents in the community living in } \\
\text { Porto, Portugal, diagnosed with moderate or severe dementia, associated } \\
\text { with functional dependence, cognitive decline, limitations in activities } \\
\text { of daily living and levels of frailty }\end{array}$ & 83 & $377 \mathrm{M}$ & 80.5 \\
\hline
\end{tabular}

$\mathrm{W}=$ women and $\mathrm{M}=$ men; $*$ or age range, in years. 
Chart 3. Quantitative-qualitative articles analyzed, 2014-2019. Belo Horizonte, Minas Gerais, 2019.

\begin{tabular}{|l|l|l|l|}
\hline Objective & $\begin{array}{l}\text { No. of older } \\
\text { adults }\end{array}$ & Sex & Average age \\
\hline $\begin{array}{l}\text { Obtain insights into the lived experiences of frailty among older people } \\
\text { to determine which forces can balance the deficits that affect frailty }{ }^{10}\end{array}$ & 121 & $\begin{array}{l}76 \mathrm{~W} \text { and } \\
45 \mathrm{M}\end{array}$ & 78.8 \\
\hline $\begin{array}{l}\text { Identify the risks that could threaten the independent life of frail older } \\
\text { adults }^{28}\end{array}$ & 29 & $\begin{array}{l}22 \mathrm{~W} \text { and } \\
7 \mathrm{M}\end{array}$ & 83.6 \\
\hline
\end{tabular}

$\mathrm{W}=$ women and $\mathrm{M}=$ men; $*$ or age range, in years.

\section{DISCUSSION}

In response to the guiding question: "what scientific evidence is there about the care process for frail older adults in the community, from the view of such individuals", it was noted that the literature covers different areas and dimensions of care. Self-, family, community, social and intersectoral care is addressed. The results were organized into four categories of analysis: frailty from the perception of the frail older person; priorities from the perception of older adults; perspectives of older adults regarding care services; interpersonal relationships in care for frail older adults.

\section{Frailty from the perception of the frail older person}

This category addresses how older adults perceive frailty. The older adults' view of frailty is recurrent as a negative, harmful, rejected and associated label, with worsening health conditions, reduced participation and increased stigmatization ${ }^{11,15,25,32}$. A qualitative study on the perception and attitude of older adults towards frailty identified a discrepancy between operationalization in clinical contexts and the understanding of older adults ${ }^{11}$. Older adults did not identify themselves as frail even when they met the objective diagnostic criteria, and this classification did not always coincide with a feeling of frailty ${ }^{11}$. For older adults, frailty was identified based on health levels and participation in physical and social activities, resulting from isolated events, temporary disabilities, old age and physical limitations ${ }^{11}$.

Frailty was described as a negative physical and psychological condition, close to disability, and reflective of common stereotypes of old age ${ }^{11}$. For many older adults, frailty was inevitable, permanent and irreversible due to aging, and composed not only of physical elements proposed in the phenotypic definition, but also mental and psychological aspects $^{25}$. Thus, for older adults, changes in health could be the cause or result of self-identification as frail, so that the diagnosis was not only information, but also a determinant for their health ${ }^{11}$. The most frail participants accepted the diagnosis more easily, as they lived with more symptoms than less frail individuals ${ }^{25}$. Even among frail older adults, there is a preference not to use the term to describe their health condition, so programs should innovate to find a form of communication that is acceptable ${ }^{25}$ and pay attention to the negative effects of the label of frail for this population ${ }^{15}$.

It was also found in literature ${ }^{4,5,15}$ that the malleability of frailty is little known among older adults, requiring health education to raise awareness of the reversibility of frailty and modify health behaviors. Older adults, who live in deprived neighborhoods, seemed to be resourceful when dealing with adversities, and were happy with their abilities. This behavior, for the authors, could mask deficits in knowledge, revealing the potential of health education to tackle the difficulties related to aging $^{4}$.

Another study addresses the understanding of frailty by older adults as a dynamic state that combines factors of balance within the scope of the individual, the environment and macrosocial factors, which influence the maintenance of a good quality of life ${ }^{10}$. Therefore, control in the area of health is multidimensional, and external factors are just as important as the active attitudes and cognitive processes used by the subjects themselves ${ }^{14}$. In contrast, there are also reports that being frail can 
facilitate obtaining assistance, care, support and benefits from others, and may function as a means to seeking improvements in care and services ${ }^{11}$.

\section{Priorities from the perception of older adults}

Identifying evidence of the priorities perceived by older adults is important ${ }^{28}$. This category shows the interest of frail older adults in remaining at home $e^{28}$ and as independent as possible, with autonomy, quality of life and the ability to deal with daily activities ${ }^{23,28}$. From the perspective of older adults, declining physical health is revealed as an accepted aspect of the aging proces ${ }^{28,40}$, with the condition of remaining independent and not disturbing others ${ }^{28}$. Preserving their capacity for self-care, remaining active social networks, not feeling lonely, manifesting fewer symptoms, as well as maintaining their autonomy, participation in the community and accessing essential services, are listed as priorities ${ }^{4,10,28}$.

Even the most frail older adults display engagement in daily activities as a subsidy for building resilience against frailty ${ }^{32}$. The perspective of frail older adults also demonstrates the experience of anxiety, insecurity, uncertainty and fear regarding frailty, when daily life becomes precarious and challenging ${ }^{18,38}$. Thus, the sense of control is reduced, and individuals seek support to adapt to their new levels of $\mathrm{frailty}^{18}$, to maintain their independence and the continuance of their personality ${ }^{38}$.

Studies have shown that many frail older adults are reluctant to ask for help or support from their social network for fear of disturbing others or concluding that receiving help is impossible ${ }^{28}$. After experiencing an acute illness, the desire remains to remain independent, to 'return to normal' and, if necessary, to find one's new normal according to preferences in one's own social context ${ }^{22}$.

From this perspective, priorities from the perspective of the frail older person are not only medical problems, but also include factors that support the maintenance of the ability to take care of oneself $f^{4,38}$. Through a logistic regression, in the bivariate analysis, frail older adults who were satisfied with their ability to take care of themselves were about eight times more likely to rate their health as good than those who were not satisfied with their ability to care for themselves ${ }^{4}$.

Among the factors that modulate the perception of control of health care among older adults, the following stand out: self-confidence in the organization of professional and/or informal care and in health management in the home environment; the clarity of the care available; as well as the perceived support of the individual's social network, health professionals, health organizations, infrastructure and services ${ }^{14}$. In contrast, a lack of interest in selfcare can be a consequence of the loss of skills, causing expectations to be lowered in this area $a^{14}$. The perception of impaired independence is associated with the clarification of its different dimensions: relative, special and social ${ }^{42}$.

\section{Perspectives of older adults regarding care services}

From the perspectives of frail older adults living in the community, important points can be made about the care provided by health services, indicating the need for more heterogeneous responses ${ }^{18}$. The articles reviewed highlight the focus on the independence of the frail older person, person-centered care and personalized assistance on topics important to the daily life of each individual to maintain their autonomy, despite their disabilities ${ }^{15,18,24,38}$. The integration of services to minimize fragmentation in the provision of services, improve communication, socialization and mobility are necessary ${ }^{15,18,24,34}$. Emotional aspects to produce comfort and well-being; the adoption of psychosocial and spiritual approaches; and the assessment of care needs and comprehensive geriatric assessments are also essential ${ }^{34}$.

The multidimensional concept of frailty requires that the subjective perspectives of older adults be considered. One article highlights the salutogenic approach in care planning as beneficial to frail older adults, based on the narratives of this population group about their daily life, in order to support the individual in their living context, allowing them to remain in their social network and to maintain satisfaction with their ability to manage everyday life $^{4}$. 
Frail older adults need a wide range of services over a long period of time due to the complex health situation and changes they experience ${ }^{36}$. In Poland, the perspective of frail older adults revealed the inadequacy of services for the needs of this population. Among the difficulties encountered when accessing health and social care were: the lack of knowledge about the existence of some services; shortages in the provision of care, lengthy waiting times and the geographical location of the services; the lack of an adequate and trained professional in the area of older adult health, the low operational level for the most vulnerable people, among others ${ }^{36}$.

The screening of frail older patients by health services must be accompanied by support interventions for older adults and their caregivers ${ }^{15}$. In primary care, studies have shown the need to invest in the interaction between patients and professionals to improve the quality of care ${ }^{27}$. In this context, the perception of the demand for care provides important information about the real care needs of frail older adults - however, more attention is often paid to physical and environmental issues than those in the psychosocial domain ${ }^{6}$. In the United Kingdom, older people evaluated the care received positively, affirmed their confidence in and the continuity of health care to avoid unplanned hospitalization by including medication, physical aids, adaptations to the home, the adoption of a healthy lifestyle and psychosocial practices $^{35}$.

Scientific evidence suggests that interventions should focus on the multidimensional perspectives of frail older adults discharged from hospital, be cautious during transition care and reorganize the integration between the primary and secondary care sectors $^{29}$. The involvement of the frail older person in their care, in decision making, in the transition of care from the hospital to the home requires improving communication and information ${ }^{29}$. For patients, the type and amount of help, access to and administration of medications, failures in communication, fear of being sick alone and concerns about activities of daily living are relevant ${ }^{29}$. In transition care, the desire also emerges that the care is individualized, integrated, centered on the needs of the client, with the patient's involvement in decision-making so that they feel supported when dealing with increased levels of frailty ${ }^{18}$. Conversely, it can be seen that the transition of care can be impaired due to fragmentation in the provision of services, the loss of control over the process in a scenario of reduced functionality, adaptation and uncertainties surrounding future support ${ }^{18}$.

For frail older adults, satisfaction with the ability to take care of oneself, having ten or less symptoms and not feeling lonely, had the best explanatory power for the frail experiences of older adults in good health due to the possibility of managing and maintaining their daily lives. ${ }^{4}$. Frail older adults with more limitations report more need of care, whether received or not received, in all domains. One study found that a younger age and a higher educational level were associated with the presence of unmet needs, a presumed cohort effect as this population is likely to have a higher expectation of health services ${ }^{6}$.

\section{Interpersonal relationships in care for frail older adults}

This category introduces the various relational aspects that modulate the care of the frail older person in the community. Interpersonal relationships, social contact, intervention in community contexts were particularly valued by this group ${ }^{14,23,31,35,36}$ as fundamental for prevention, adherence to interventions and the reduction of frailty ${ }^{23}$.

Having a goal in life, feeling useful and remaining socially active can lead to fewer medical interventions - a perspective desired by this public ${ }^{23}$. The studies highlighted the importance of being interested in the experiences of frail older adults; offering home visits, listening and providing psychosocial support in the community ${ }^{23}$; and recognizing the incidence of anxiety and depression in this population ${ }^{31}$. Similarly, another study maintains that the family support network, relatives, neighbors and friends reduced anxiety, hospitalization, and were recognized as fundamental to well-being ${ }^{35}$. There is a correlation between social support and resilience, contributing to a better quality of life for older adults ${ }^{35,37}$. Social and community life is expressed as a possibility for compensating for losses ${ }^{42}$. Likewise, social ties with family members, neighbors, caregivers, local authorities emerge as an important source of 
meaning ${ }^{30}$. The social roles played by older adults and their social networks change over time, with frail older adults tending to maintain a small network because of the difficulty of establishing a new network due to frailty and being selective in the search for relationships ${ }^{30}$.

Another factor is to recognize loneliness as a potential clinical problem for the frail older adult, who uses health services more often ${ }^{39}$. One study addresses the perception of frail older adults about existential loneliness based on the Emmy van Deurzen theoretical model. In this model the life of older adults is characterized by waiting, experiencing different loss processes: in their social environment, social roles, and in their body, among others $^{33}$. In this article, the scientific evidence on the care process for the frail older adult indicates that, in the older person's view, being connected through social relationships does not mean a great number of contacts, but rather deep conversations about significant issues, while, on the other hand, a feeling of existential loneliness arises when the choices made disregard the opinions of older adults ${ }^{33}$. Similarly, the literature recognizes that a feeling of depersonalization can occur when older people are not involved in decisions ${ }^{2}$.

Another study shows that the significant union with relatives, friends and the health team (through person-centered care), as well as the experience of living a meaningful life and of having their feelings recognized, relieve existential loneliness and contribute to the process of care ${ }^{26}$. The prevalence of feelings of loneliness in the frail older population is similar to that of other older adults. However, more frail and lonelier older adults had worse general physical and psychosocial health conditions and used health services more than non-lonely individuals ${ }^{39}$.

The meanings of life for frail older adults may still be within the scope of their different needs. In the light of Derkx's theoretical model, the needs for the frail older person were: to continue their daily activities, to have a purpose for the future, to pursue hobbies, to maintain a connection with their children and grandchildren; to evaluate their way of life as morally worthy; to maintain the level of control and autonomy in their lives; to value themselves, to be recognized and respected by others; to realize the continuity of their identity; to maintain a connection to relatives and friends as a support to others despite being frail, or a connection in the spiritual realm; feelings of excitement through transcendence via art, culture, nature and the events of life ${ }^{30}$. Thus, the loss or scarcity of meaning manifests itself as a result of aging or a restricted connection network, which may occur due to a lack of purpose, coherence or connection, thus, the importance of the social environment is evident in maintaining the meaning of life ${ }^{30}$. The results and discussion are summarized in Figure 2.

Limitations of the present review include the fact that it does not address the perspectives of other actors involved in the care settings for frail older adults in the community. However, it contributes to considerations of the point of view of frail older adults, which is little known ${ }^{11,18}$ when planning health actions and public policies aimed at such individuals. Thus, considering the psychosocial needs of frail older adults ${ }^{6}$ provides insights into the risks that this population group perceives as a priority ${ }^{28}$ and their coping strategies ${ }^{40}$. 


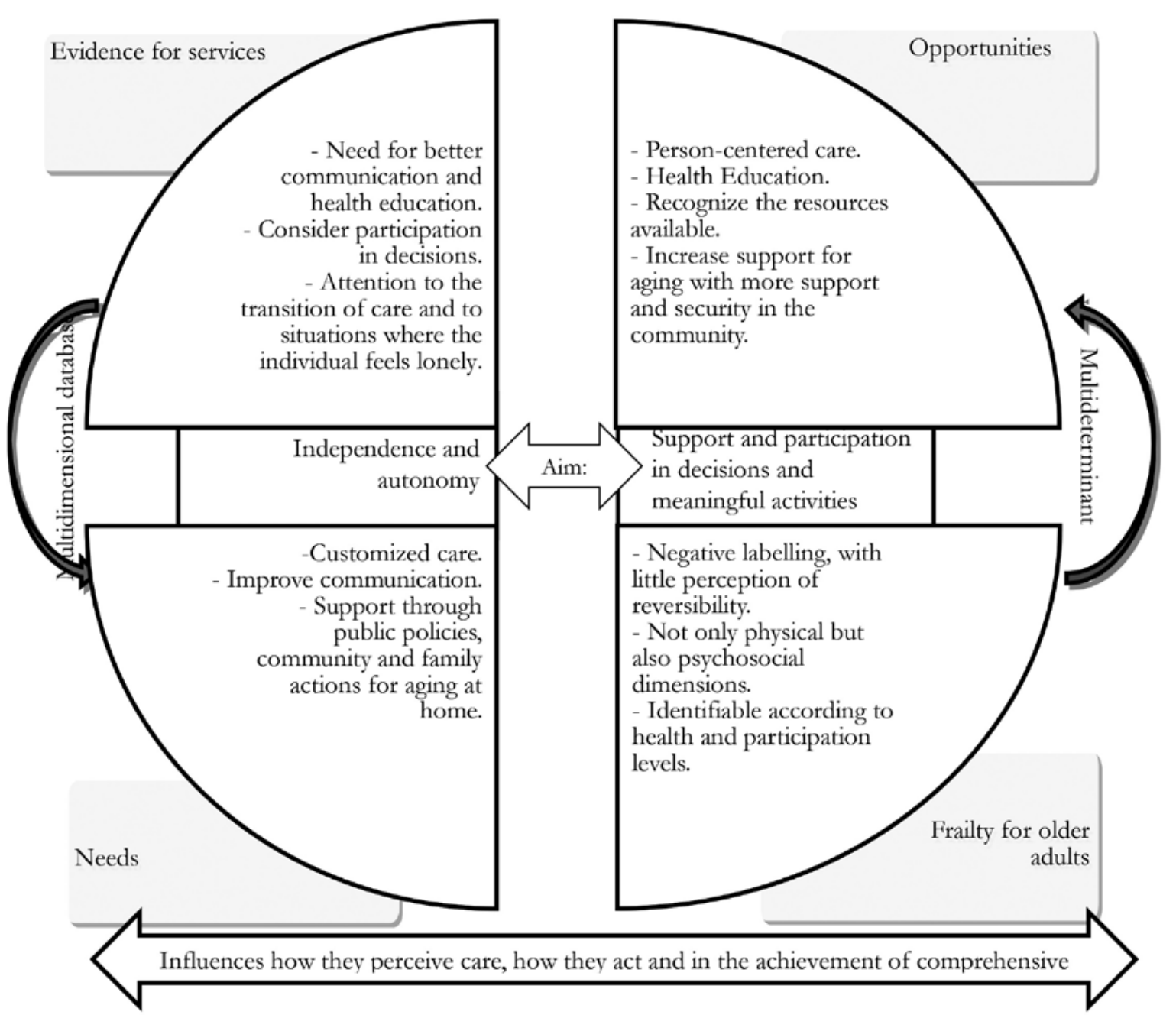

Source: Prepared by the authors.

Figure 2. Scientific evidence about the process of care of frail older adults residing in the community, from the perspective of the older adults. Belo Horizonte, Minas Gerais, 2019.

\section{CONCLUSION}

In this review, most studies revealed frailty from the perspective of older adults with various specific characteristics, ranging from clinical operations to influence in care. Frailty appears as a predominantly negative label for the frail older person with little perception of reversibility. Scientific evidence on care from the perspective of the frail older person in the community shows that the focus of care is to maintain their capacity, functionality and participation in decisions. However, this condition also depends on the availability of the support network, community resources and public policies. Thus, the comprehensive care model, support for older adults and their caregivers is necessary to increase assistance for aging with more support and security for the longest possible time.

The review revealed that services need to offer personalized, person-centered assistance, which also includes psychosocial aspects and the narratives and life contexts of the older adults, with special attention to transition care and preventing loneliness among frail older adults. It was also observed that, for the frail older person in the community, it is necessary 
to improve communication, considering the choices based on the interests of this public. Thus, attention should be paid to the fact that the meaning of life for this population also focuses on communication, and so an ethical posture in caring for the frail older person involves listening to such individuals.

The articles examined in this study reflected the lack of consensus regarding the measurement of frailty. The publications are concentrated in developed countries which have been experiencing the aging process for a longer time, thus focusing on the greater challenges in developing countries. The demand for care for the frail older population is emphasized in the articles that comprised this review, an increasingly important perspective in the

\section{REFERENCES}

1. Organização Mundial De Saúde. Resumo Relatório Mundial de envelhecimento e Saúde. Genebra: Suíça; 2015.

2. D'Avanzo B, Shaw R, Riva S, Apostolo J, BobrowichCampos E, Kurpas D, et al. Stakeholders' views and experiences of care and interventions for addressing frailty and pre-frailty: a meta-synthesis of qualitative evidence. PloS One. 2017;12(7): e0180127 [22 p.].

3. Lim WS, Wong SF, Leong I, Choo P, Pang WS. Forging a frailty-ready healthcare system to meet population ageing. Int J Environ Res Public Health. 2017;14(12):1-16.

4. Ebrahimi Z, Dahlin-Ivanoof S, Eklund K, Jakobsson A, Wilherlmson K. Self-rated health and healthstrengthening factors in community-living frail older people. J Adv Nurs. 2015;71(4):825-36.

5. Andrade AN, Fernandes MGM, Nóbrega MML, Garcia TR, Costa KNFM. Análise do conceito fragilidade em idosos. Texto \& Contexto Enferm. 2012;21(4):748-56.

6. Hoogendijk EO, Muntinga ME, Leeuwen KM, Horst HE, Deeg DJ, Frijters DH, et al. Self-perceived met and unmet care needs of frail older adults in primary care. Arch Gerontol Geriatr. 2014;58:37-42.

7. Berglund $\mathrm{H}$, Hasson $\mathrm{H}$, Kjellgren $\mathrm{K}$, Wilhelmson $K$. Effects of a continuum of care intervention on frail older persons' life satisfaction: a randomized controlled study. J Clin Nurs. 2015;24(7-8):1079-90. current scenario in society. A review of related topics, such as the analysis of interventions with frail older adults in the community, is suggested.

The current knowledge if care for the frail older person from the perspective of care recipients in the community supports decisions and improvements that favor the quality of life of this population. In this way, health professionals and public policies can carry out actions in line with the needs of this public. Furthermore, the meanings and senses of the experiences of frailty and care influence the way older adults perceive and act when dealing with this process, in order to achieve comprehensive care and ensure the quality of life of this population.

Edited by: Ana Carolina Lima Cavaletti
8. Ayres JRCM. Cuidado: trabalho e interação nas práticas de saúde. Rio de Janeiro: CEPESC; 2009.

9. Pinheiro RM, Mattos R, organizadores. Razões públicas para a integralidade em saúde: o cuidado como valor. Rio de Janeiro: IMS/UERJ; 2007.

10. Dury S, Dierckk E, Vorst A, Elst M, Fret B, Duppen $\mathrm{D}$, et al. Detecting frail, older adults and identifying their strengths: results of a mixed-methods study. BMC Public Health. 2018;18(1):1-13.

11. Warmoth K, Lang I, Phoenix C, Abraham C, Andrew M, Hubbard RE, et al. 'Thinking you're old and frail': a qualitative study of frailty in older adults. Ageing Soc. 2016;36:1483-1500.

12. Archibald MM, Ambagtsheer R, Beilby J, Chehade MJ, Gill TK, Visvanathan R, et al. Perspectives of failty and frailty screening: protocol for a collaborative knowledge translation approach and qualitative study of stakeholder understandings and experiences. BMC Geriatr. 2017;17(87):1-8.

13. Gutierrez DMD, Minayo MCS. Produção de conhecimento sobre cuidados da saúde no âmbito da família. Ciênc Saúde Colet. 2010;15(Suppl 1):1497-1508.

14. Claassens L, Widdershoven GA, van Rhijn SC, van Nes F, van Groenou MIB, Deeg DJ, et al. Perceived control in health care: a conceptual model based on experiences of frail older adults. J Aging Stud. 2014;31:159-70. 
15. Shaw RL, Gwyther H, Holland C, Bujnowska M, Kurpas D, Cano A, et al. Understanding frailty: meanings and beliefs about screening and prevention across key stakeholder groups in Europe. Ageing Soc. 2017:1-30.

16. Lain R, Ignaszewski C, Klingmann I, Cesario A, Boer WI. SPRINTT and the involvement of stakeholders: strategy and structure. Aging Clin Exp Res. 2017;29(1):65-7.

17. Brasil. Ministério da Saúde. Diretrizes para o cuidado das pessoas idosas no SUS: proposta de modelo de atenção integral. Secretaria de Atenção à Saúde. Distrito Federal: MS; 2014.

18. Walker R, Johns J, Halliday D. How older people cope with frailty within the context of transition care in Australia: implications for improving service delivery. Health Soc Care Community. 2015;23(2):216-24.

19. Mendes KDS, Silveira RCCP, Galvão CM. Revisão integrativa: método de pesquisa para a incorporação de evidências na saúde e na enfermagem. Texto Contexto Enferm. 2008;17(4):758-64.

20. Whittemore R, Knafl K. The integrative review: updated methodology. J Adv Nurs. 2005;52(5):546-53.

21. Stetler CB, Morsi D, Rucki S, Broughton S, Corrigan $B$, Fitzgerald J, et al. Utilization focused integrative reviews in a nursing service. Appl Nurs Res. 1998;11(4):195-206.

22. Etkind SN, Lovell N, Nicholson CJ, Higginson IJ, Murtagh FEM. Finding a 'new normal' following acute illness: a qualitative study of influences on frail older people's care preferences. Palliat Med. 2019;33(3):301-11.

23. Avgerinou C, Gardner B, Kharicha K, Frost R, Liljas A, Elaswarapu R, et al. Health promotion for mild frailty based on behaviour change: perceptions of older people and service providers. Health Soc Care Community. 2019;27:1333-43.

24. Frost R, Kharicha K, Jovicic A, Liljas A, Iliffe S, Manthorpe J, et al. Identifying acceptable components for home-based health promotion services for older people with mild frailty: A qualitative study. Health Soc Care Community. 2018;26:393-403.

25. Schoenborn NL, Rasmussen SEVP, Xue Q, Walston JD, McAdams-Demarco MA, Segev DL, et al. Older adults' perceptions and informational needs regarding frailty. BMC Geriatr. 2018;18:1-7.

26. Sjöberg M, Edberg A, Rasmussen BH, Beck I. Being acknowledged by others and bracketing negative thoughts and feelings: Frail older people's narrations of how existential loneliness is eased. Int J Older People Nurs. 2019;14: e12213 [9 p.].
27. Vestjens L, Cramm JM, Nieboer AP. Quality of primary care delivery and productive interactions among community living frail older persons and their general practitioners and practice nurses. BMC Health Serv Res. 2019;19(1)1-12.

28. Verver D, Merten H, Robben P, Wagner C. Perspectives on the risks for older adults living independently. Br J Community Nurs. 2017;22(7): $338-45$.

29. Andreasen J, Lund H, Aadahl M, Sorensen E. The experience of daily life of acutely admitted frail elderly patients one week after discharge from the hospital. Int J Qual Stud Health Well-being. 2015;10:1-11.

30. Duppen D, Machielse A, Verté D, Dury S, Donder L, Consortium D. Meaning in Life for Socially Frail Older Adults. J Community Health Nurs. 2019;36(2):65-77.

31. Frost R, Nair P, Aw S, Gould RL, Kharicha K, Buszewicz M, et al. Supporting frail older people with depression and anxiety: a qualitative study. Aging Ment Health. 2019:1-9.

32. Bujnowska-Fedak MM, Gwyther H, Szwamel K, D'Avanzo B, Holland C, Shaw RL, et al. A qualitative study examining everyday frailty management strategies adopted by Polish stakeholders. Eur J Gen Pract. 2019;25(4):197-204.

33. Larsson H, Edberg A, Bolmsjö I, Rämgard M. Contrasts in older persons' experiences and significant others' perceptions of existential loneliness. Nurs Ethics. 2019;26(6):1623-37.

34. Abreu W, Tolson D, Jackson GA, Staines H, Costa $\mathrm{N}$. The relationship between frailty, functional dependence, and healthcare needs among communitydwelling people with moderate to severe dementia. Health Soc Care Community 2019;27:642-53.

35. Dew R, Wilkes S. Attitudes, perceptions, and behaviours associated with hospital admission avoidance: a qualitative study of high-risk patients in primary care. Br J Gen Pract. 2018:460-8.

36. Kurpas D, Gwyther H, Szwarnel K, Shaw RL, D'Avanzo B, Holland CA, et al. Patient-centred access to health care: a framework analysis of the care interface for frail older adults. BMC Geriatr. 2018;18:1-17.

37. Gibb H. Determinants of resilience for people ageing in remote places: a case study in northern Australia. Int J Ageing Later Life. 2018;11(2):9-34.

38. Skilbeck JK, Arthur A, Seymour J. Making sense of frailty: an ethnographic study of the experience of older people living with complex health problems. Int J Older People Nurs. 2018;13(1):e12172 [11 p.]. 
39. Taube E, Kristensson J, Sandberg M, Midlov $\mathrm{P}$, Jakobsson U. Loneliness and health care consumption among older people. Scand J Caring Sci. 2015;29(3):435-43.

40. Bielderman A, Schout G, Greef M, Schans C. Understanding how older adults living in deprived neighbourhoods address ageing issues. $\mathrm{Br} \mathrm{J}$ Community Nurs. 2015;20(8):394-9.
41. Sandberg M, Jakobsson U, Midlöv P, Kristensson J. Case management for frail older people: qualitative study of receivers' and providers' experiences of a complex intervention. BMC Health Services. 2014;14:2-12.

42. Hillcoat-Nallétamby S. The meaning of "independence" for older people in different residential settings. J Gerontol Ser B Psychol Sci Soc Sci. 2014;69(3):419-30. 